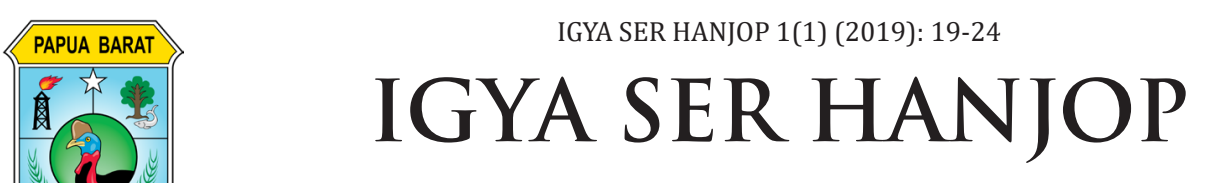

p-ISSN: 2716-0491

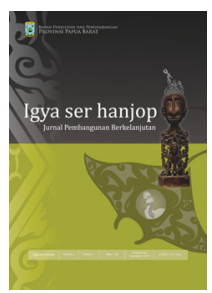

\title{
Membangkitkan Tradisi yang Telah Mati
}

\author{
George Mentansan ${ }^{1 *}$, Phil I Ketut Ardhana ${ }^{2}$, \\ I Nyoman Suarka ${ }^{3}$, I Nyoman Dhana ${ }^{4}$ \\ ${ }^{1}$ Universitas Papua, Manokwari \\ Jl. Gn. Salju, Manokwari Barat, Amban, Manokwari, Papua Barat 98314 \\ ${ }^{2,3,4}$ Universitas Udayana Denpasar Bali \\ Jl. P.B. Sudirman, Dangin Puri Klod, Denpasar, Bali 80234
}

Dikirim: 7 Oktober 2019; Direvisi: 29 Oktober 2019; Disetujui: 18 Desember 2019

\begin{abstract}
Raja Ampat Indigenous People is a community of fisherman that practices one of its traditions, called Sasi. Research results show Raja Ampat has become the largest conservation area in Indonesia with a zoning system established under government regulations. However, this zoning system could not solve the the problem of marine ecosystem destruction, as there are still desctructive fishing activities to coral reefs. Economic reasons, and the zoning system implemented by the government and marine conservation NGOs, which is considered as a product from outside/modern, becoming one of the reasons for the community to disobey, and often doing destructive avtivities in the zonation. Therefore, the activity of Sasi needs to be reactivated and used to support the marine conservation efforts, based on indigenous/local people with the role of traditional and religious leaders in the rituals, so that coral reef desctruction and damages can be avoided.
\end{abstract}

Keywords : tradition, sasi, Raja Ampat

\section{Intisari}

Masyarakat Adat Raja Ampat merupakan masyarakat nelayan yang mempraktekkan salah satu tradisinya yaitu Sasi. Hasil penelitian menunjukkan bahwa Raja Ampat menjadi kawasan konservasi perairan terluas di Indonesia dengan sistem zonasi namun tidak menyelesaikan persoalan kerusakan ekosistem perairan karena masih terjadi aktivitas penangkapan yang merusak terumbu karang. Dalih ekonomi, dan sistem zonasi yang diterapkan oleh pemerintah dan LSM konservasi di perairan merupakan produk luar/modern menjadi salah satu alasan masyarakat untuk tidak taat dan sering melakukan pelanggaran-pelanggaran pada zonasi tersebut. Maka, kegiatan Sasi dibangkitkan kembali dan digunakan untuk mendukung upaya konservasi zonasi perairan yang berbasis kepada masyarakat adat dengan peran tokoh adat dan agama dalam ritual sehingga pelanggaran dan kerusakan terumbu karang tidak terjadi.

Kata kunci : tradisi, sasi, Raja Ampat.

\section{LATAR BELAKANG}

Praktik kearifan lokal masyarakat Raja Ampat sebagai masyarakat nelayan lebih banyak tampak pada kehidupan sebagai seorang penangkap ikan dilaut. Kearifan lokal (local wisdom) dan pengetahuan lokal (local knowledge) seperti : tempat keramat, tempat sakral, tempat pamali dan sebutan lokal lain banyak ditemui di daerah Raja Ampat. Kearifan tradisional/lokal adalah sistem sosial, politik, budaya, ekonomi dan lingkungan dalam lingkup komunitas lokal (Pattiselanno \& Mentansan, 2010). Pengertian lain namun senada yakni kearifan lokal dapat dikatakan sebagai prinsipprinsip dan cara-cara tertentu yang dianut, dipahami dan diaplikasikan oleh masyarakat lokal dalam berinteraksi dan berinterelasi dengan lingkungannya dan ditransformasikan dalam bentu sistem nilai dan norma adat (Permana et al., 2011). Definisi berbeda dan

\footnotetext{
* Korespondensi Penulis

Phone : +6281344059484

Email : georgementansan@gmail.com
} 
sangat antropologis tentang kearifan lokal yaitu lokasi bersemayamnya roh-roh nenek moyang, asal-usul suku, bersemayamnya roh-roh orang mati karena manusia memiliki keyakinan akan adanya kekuatan gaib dalam hal-hal yang luar biasa dan yang menjadi sebab timbulnya gejala-gejala yang tak dapat dilakukan oleh manusia biasa (Koentjaraningrat, 2008, p. 60). Sehingga dalam praktik mata pencaharian mereka tempat itu dianggap area yang tidak boleh disentuh dan dimasuki dengan alasan apapun karena akan berdampak buruk dan menimbulkan bencana bagi masyarakat maupun individu yang melanggarnya. Selain situs dan area keramat secara tradisi diyakini menjadi ruang kendali dan ruang sakral masyarakat, ada pula sebuah praktek kearifan lokal yang dilakukan oleh masyarakat sejak dahulu kala yaitu sasi.

Sasi adalah bentuk kearifan lokal masyarakat pesisir dan masyarakat pulau di Raja Ampat dimana kearifan ini dilakukan untuk mengsakralkan suatu wilayah atau tempat dalam kurun waktu tertentu. Dalam tesis Mcleod (2007) didefinisikan bahwa"Sasi is an Ambonese-Malay term which likely derives from the Malay word "saksi" meaning "to witness" or "witness". Sasi laut refers to rules and regulations controlling marine resources and includes restrictions on fishing gear, species harvested, time of harvest, location of harvest, and who is allowed to harvest natural resources" (Bailey \& Zerner, 1991)

Maksud dilakukannya sasi adalah agar wilayah ini tidak dimasuki oleh siapapun sehingga ikan, teripang, dan jenis-jenis biota yang ada dilokasi itu dapat berkembangbiak dengan baik dan pada waktunya dipanen mencukupi untuk dijual dan dari hasil penjualan itu digunakan bagi kepentingan pembangunan sebuah rumah ibadah, syukuran hari-hari gerejani atau hari raya lainnya. Sasi dilakukan pada wilayah tertentu dengan luasan yang tidak terlalu besar dan hanya dilakukan dalam bentuk ritual-ritual tradisional dengan pelibatan anggota masyarakat tertentu dalam sebuah kampung. Tiap kampung melakukan sasi dengan kepentingan yang beragam, waktu yang variatif dan dalam tiap kegiatan prosesi ritual sasi ini lebih banyak dilakukan oleh tokoh-tokoh agama.

Perkembangan dan perubahan yang terjadi pada masyarakat Raja Ampat menyebabkan kegiatan sasi telah ditinggalkan karena masyarakat Raja Ampat dalam interaksinya dengan nelayan dari luar seperti, Buton, Bugis, Makasar, Ternate dan Tidore dan nelayan asal Kabupaten Sorong yang telah menggunakan alat tangkap modern dan mendapatkan hasil dalam jumlah yang banyak dan cepat mendorong masyarakat lokal untuk beradaptasi dan mulai menggunakan caracara dari nelayan luar, menangkap ikan dengan bom, potasium dan racun ikan menjadi suatu kebiasaan yang sering dilakukan. Masyarakat memberikan ruang dan tempat menangkap ikan yang dahulu dianggap sebagai lokasi keramat dan tempat sakral kepada nelayan dari luar untuk menangkap ikan dilokasi tersebut yang dipengaruhi oleh faktor agama modern (Kristen dan Islam), modernisasi, modernitas dan dunia global saat ini.

Tradisi sasi ini kemudian lambat laut ditinggalkan dan mulai mengadopsi praktekpraktek menangkap ikan dengan teknologi modern yang menawarkan efektifitas dan efisiensi bagi masyarakat tanpa memperdulikan konsekuensi-konsekuensi dari tindakan masyarakat. Kerusakan terumbu karang, padang lamun, dan biota laut yang rusak akibat cara menangkap ikan dengan bom, racun ikan, dan potasium tidak menjadi pertimbangan bagi nelayan lokal. Keberlangsungan sumber daya laut yang aman, menyediakan cukup cadangan makanan tidak dipertimbangkan untuk generasi masa depan di kampungkampung Raja Ampat. Fenomena ini menjadi potret dan gambaran perubahan signifikan dalam masyarakat adat Raja Ampat sebagai masyarakat nelayan yang sejak dahulu menjaga hubungan yang harmonis kehidupannya dengan alam terutama kehidupan pesisir, pulau, dan perairan. Perubahan-perubahan sosial dan budaya yang terjadi disebabkan oleh berbagai faktor diantaranya adalah interaksi masyarakat lokal yang intens dengan orang luar, adanya hasrat, dan keinginan untuk memenuhi kebutuhan yang semakin kompleks mendorong masyarakat untuk beradaptasi dan menerima perubahan bawaan orang luar ke daerahnya. Oleh sebab itu perubahan sosial dapat dibayangkan sebagai perubahan yang terjadi didalam atau mencakup sistem sosial atau lebih tepatnya terdapat perbedaan antara keadaan sistem tertentu dalam jangka waktu berlainan (Sztompka, 2005, p. 3). Perubahan 
ini nampak nyata dari hilangnya tradisi lokal (local tradition) seperti kearifan yang dianut kelompok manusia nelayan Raja Ampat.

\section{Metode}

Penelitian ini menggunakan metode kualitatif yang menurut Prastowo (2014, p. 12) bahwa metodologi kualitatif adalah prosedur penelitian yang akan menghasilkan data deskriptif kualitatif berupa kata-kata tertulis atau lisan dari orang-orang dan perilaku yang diamati. Instrumen utama dalam penelitian ini adalah peneliti sendiri serta didukung dengan alat bantu seperti buku catatan, tape recorder, kamera dan jadwal penelitian. Pengumpulan data dilakukan dilakukan dengan cara observasi, wawancara mendalam dan dokumentasi.

Teknik analisis data yang digunakan mengacu pada model Miles dan Huberman dalam Prastowo (2009; 2014, p. 12) bahwa analisis data kualitatif adalah suatu proses analisis yang terdiri dari tiga alur kegiatan yang terjadi secara bersamaan, yakni reduksi data, penyajian data dan penarikan kesimpulan atau verifikasi. Hasil analisis data kemudian disajikan dalam bentuk deskriptif naratif.

\section{HASIL DAN PEMBAHASAN}

Babak baru kehidupan masyarakat di Raja Ampat terjadi saat daerah ini dijadikan sebagai kabupaten baru yang terkenal dengan istilah kabupaten bahari atau slogan kabupaten yang merupakan "surga terakhir di bumi". Kabupaten hasil pemekaran dari kabupaten Sorong pada tahun 2002, menjadi tonggak awal perubahan dan perkembangan pesat daerah ini. Waisai sebagai ibukota Raja Ampat menjadi pusat ekonomi, persebaran uang, dan berpusatnya proyek modernitas yang menurut Calinescu (Yudhie, 2005, p. 32) diartikan sebagai kondisi sosial budaya masyarakat yang menyiratkan perubahan paradigm yang diperoleh dengan jalan pintas dari bentuk lama ke bentuk baru. Masyarakat berkembang dari masyarakat tradisional menuju ke masyarakat modern sehingga modernitas identik dengan perubahan kebudayaan dunia yang sedang berkembang yang terkait dengan proses modernisasi. Oleh Karena itu modernisasi berarti berlangsungnya proyek mencapai kondisi modernitas yang digerakkan semangat rasionalitas instrumental. Disini modernisasi di tandai oleh pemutusan hubungan yang tegas dengan nilai-nilai tradisional, berkembangnya sistem ekonomi kapitalis progresif, rasionalisasi administratif, dan deferensiasi sosial-budaya. Dengan kekayaan-kekayaan sumber daya alam perairan dan multikultur masyarakat Raja Ampat menjadikan daerah ini telah melejit sangat cepat terkenal pada tingkat nasional dan internasional dibandingkan dengan kabupaten lain yang dimekarkan bersamaan.

\section{A. Upaya Perlindungan dan Pelestarian Ekosistem Raja Ampat}

Hasrat untuk mengembalikan, mengatur dan mengelola kerusakan dan keberlangsungan terumbu karang, ikan karang, padang lamun, dan moluskayang berada di perairan Raja Ampat agar surga itu tetap melekat pada kabupaten Raja Ampat, maka pemerintah gencar dan bergerak cepat menggandeng berbagai pihak diantaranya lembaga swadaya masyarakat yang peduli lingkungan seperti: CI (conservation international), TNC (The Nature Conservation), dan lembaga konservasi lokal yang intens mendorong terciptanya sebuah budaya baru yang disebut dengan budaya konservasi di sebagian besar perairan Raja Ampat dengan dalih menyelamatkan sumberdaya perairan laut demi masa depan generasi Raja Ampat. Sistem zonasi yang ditetapkan melalui aturan negara dalam hal ini pemerintah daerah dan pusat telah menguasai sebagian besar perairan Raja Ampat dan dengan gerakan-gerakan moralitas kontemporer wilayah konservasi perairan di daerah ini mencapai kurang lebih 1,3 juta hektar. Tidak tanggung-tanggung perairan Raja Ampat telah dikonservasi dalam tujuh Kawasan Konservasi Perairan Daerah (KKPD) seperti kawasan konservasi perairan daerah (KKPD) Misool, Kofiau, Teluk Mayalibit, Ayau, Selat Dampier (Perbup Raja Ampat), dan satu Suaka Alam Perairan (SAP) yang dikelola oleh Kawasan Konservasi Perairan Nasional (KKPN) yang berkantor di Kupang (Profil KKPN SAP Raja Ampat).

Sistem zonasi kemudian merupakan sebuah budaya modern yang dilakukan di perairan Raja Ampat dengan harapan sistem zonasi ini dapat menjadi model pengelolaan dan pemanfaatan sumber daya perairan secara arif dan bijaksana dalam mengurangi kerusakan 
ekosistem perairan Raja Ampat karena perilaku tangkap masyarakat yang tidak ramah lingkungan. Hal ini dapat disebabkan karena di Indonesia masyarakat nelayan merupakan salah satu golongan masyarakat yang dianggap miskin secara absolut, bahkan paling miskin di antara penduduk miskin (Prihandoko et al., 2011). Sistem zonasi dibentuk dengan berbagai zona seperti zona inti yang merupakan wilayah yang sama sekali tidak boleh diganggu atau dimasuki, zona pemijahan yang merupakan tempat bertelurnya biota laut dan zona pemanfaatan yang merupakan tempat yang boleh digunakan oleh masyarakat. Tujuan dilakukannya sistem zonasi ini agar masyarakat pesisir dan pulau di Raja Ampat dalam melakukan aktivitas penangkapan ikan mengetahui lokasi zonasi dan dapat mematuhinya guna mengurangi kerusakan dan memperbaiki kerusakan terumbu karang akibat pola tangkap masyarakat yang merusak lingkungan. Namun ternyata sistem zonasi yang dilakukan di perairan ini tidak luput dari masalah penangkapan dan pengambilan hasil laut dengan cara yang merusak lingkungan. Nelayan lokal berani untuk mengambil ikan dengan cara-cara yang merugikan lingkungan dan berafiliasi dengan nelayan dari luar untuk memasuki zona-zona yang telah ditetapkan di atas tanpa kecuali zona larang tangkap dan pemijahan.

\section{B. Penggalian dan Pengintegrasian Zonasi dan Sasi}

Pelanggaran-pelanggaran yang terjadi pada sistem zonasi menyebabkan sistem sasi ini kemudian dibangkitkan kembali sebagai bentuk konservasi berbasis kearifan lokal dengan harapan perlindungan laut dilakukan oleh partisipasi aktif masyarakat lokal demi masa depan generasinya. Kegiatan sasi (penutupan wilayah penangkapan untuk sementara) mulai digalakkan di daerah pemukiman penduduk pada masyarakat-masyarakat plural dan multietnis dalam balutan ritual agamis. Artinya pelibatan tokoh agama dan tokoh adat sebagai corong masyarakat menjadi garda terdepan dalam menginisiasi proses pelaksanaan sasi di wilayahnya masing-masing. Sasi dengan ritual agama kristen diyakini akan menimbulkan efek ketakutan yang tinggi karena melalui ayat-ayat Firman Tuhan yang digunakan dalam melakukan sasi berdampak besar bagi masyarakat yang melakukan pelanggaran atau mengambil hasil laut pada lokasi yang di sasi. Pada poros ini masyarakat Raja Ampat sedang digiring pada "kristogenesi"yaitu manusia berada dalam proses 'amorisasi' menuju kesatuan baru yakni iman dan ilmu tidak bertentangan, melainkan harmonis. Ilmu mendukung agama dan agama mendukung ilmu. Dalam kristus kita membangun suatu persaudaraan baru. Kita dipanggil untuk menjadi satu tubuh yakni Tubuh Mistik Kristus. Kristus adalah Pusat dan Sentrum seluruh alam semesta" (Snijders, 2004, p. 202).

Sanksi dari pelanggaran pada wilayah sasi diyakini biasanya berupa dosa, sakit parah, dan bisa menimbulkan kematian sehingga ketakutan untuk melanggar cukup tinggi pada daerah yang telah dibuat sasi. Peran dan fungsi tokoh agama pun mulai menemukan wujudnya. Statusnya sebagai tokoh adat dan tokoh masyarakat mendapat tempat penting dalam kehidupan sosial budaya masyarakat lokal yang disebabkan oleh kepentingankepentingan untuk menjalankan kegiatan konservasi berbasis Sasi di wilayah Raja Ampat. Sasi ini digunakan untuk suatu tujuan yang secara rasional dan logis dapat diterima karena merupakan suatu tindakan budaya untuk menjaga harmonisasi kehidupan manusia dan alam, manusia dengan sumber kehidupan dan menjamin terpenuhinya kantongkantong makan dari masyarakat setempat. Memimjam istilah Bourdieu (2010, pp. 14-17) yaitu 'habitus dan arena' untuk menjelaskan fenomena ini. Sasi digunakan sebagai senjata 'logika permainan'(feel for the game), sebuah 'rasa praktis' (practical sense) yang mendorong agen-agen bertindak dan bereaksi dalam situasi-situasi spesifik dengan suatu cara yang tidak bisa dikalkulasikan sebelumnya, dan bukan sekadar kepatuhan sadar pada aturanaturan. Ia lebih mirip seperangkat disposisi yang melahirkan praktik dan persepsi. "Arena" dalam sasi di masyarakat Raja Ampat terutama tokoh adat dan agama sebagai agen-agen tidak bertindak dalam ruang hampa, melainkan di dalam situasi-situasi sosial konkret yang diatur oleh seperangkat relasi sosial yang objektif. Sasi dibangkitkan dengan suatu ritual yang berslogankan konservasi oleh para penguasa dan disakralkan melalui suatu tindakan religi agama modern dan hukum negara.

Negara menjadi sutradara dan aktor utama 


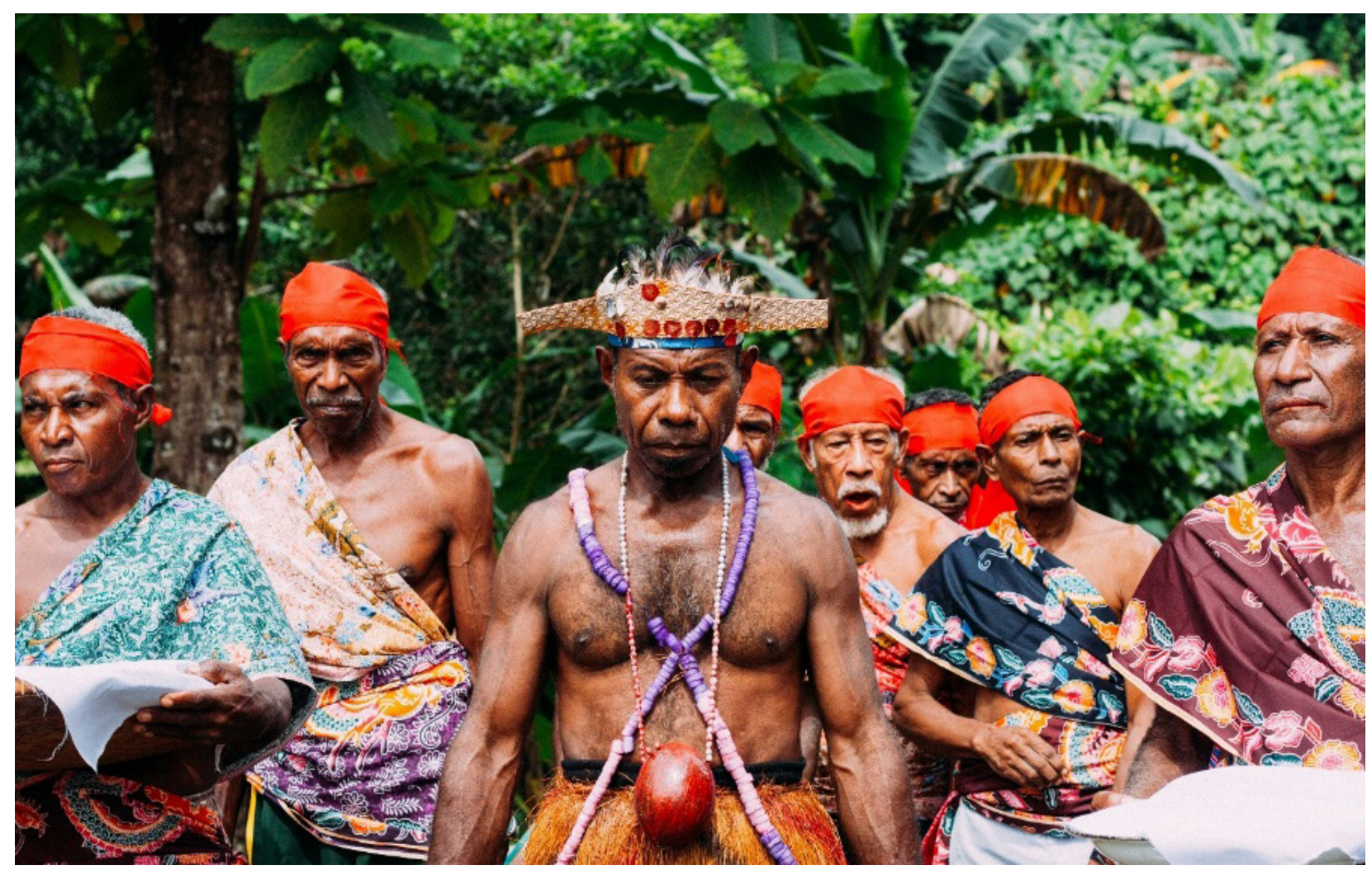

Gambar 1. Upacara Sasi di Teluk Mayalibit dalam Rangka Deklarasi Kawasan Konservasi Laut

dalam tindakan ini seperti yang diungkapkan oleh Patria (2003, pp. 136-137) dalam teori hegemoninya yang salah satunya menggagas tentang kepentingan ekonomi, negara (political society), dan masyarakat sipil (civil society) menjadi dasar negara memegang peranan dan kuasa penuh untuk menghegemoni masyarakat dalam menjalankan tujuan dan ambisinya. Relasi kuasa ini telah menghegemoni masyarakat adat Raja Ampat karena dengan kuasa (power) yang dimiliki telah memantapkan barisannya dari hulu hingga hilir dari produk hukum sampai implementasi di masyarakat yang disebarkan melalui agen-agen perubahan yang memiliki kuasa (power) secara adat dan agama. tokoh-tokoh tersebut ditambah dengan tokoh pemerintah kampung diyakini memiliki kuasa untuk mempengaruhi sehingga mereka digunakan untuk menancapkan budaya Sasi sebagaimana yag diungkapkan oleh Giddens (2011, p. 18) bahwa " ada dugaan bahwa menjadi agen berarti harus mampu menggunakan gugusan kekuasaan kausal, termasuk mempengaruhi kekuasaankekuasaan yang disebarkan orang lain.

Sasi sebagai sebuah bola panas telah membakar dan membunuh ruang kebebasan masyarakat karena berdasarkan data empiris, kegiatan sasi telah dipraktekkan dan dijadikan sebagai bentuk konservasi tradisional yang bersanding mesra dengan bentuk konservasi modern yaitu sistem zonasi. Pasangan serasi ini ternyata diperkuat oleh pengakuan masyarakat dan secara sukarela masyarakat adat menyerahkan sebagian wilayah adatnya untuk dijadikan sebagai wilayah sasi dengan menyerang, menguasai, dan mengendalikan logika masyarakat adat Raja Ampat. Sasi ini digunakan sebagai sebuah bentukan wacana kearifan praktissebagaimanayangdiungkapkan oleh Paul Recoeur bahwa "kearifan praktis merupakan seni bertindak secara tepat ketika konflik-konflik muncul mengatasi prinsipprinsip yang dijustifikasi secara komunikatif" Kaplan dan Manners (1999, pp. 175-176). Sasi dijadikan seni dan solusi pertama dan terakhir peran masyarakat dalam menjaga kekayaan sumber daya alam karena dengan kegiatan sasi masyarakat berpartisipasi aktif menjaga dan melindungi dan secara arif memanfaatkan dan mengelola potensi perikanan dan kelautannya termasuk pola pola penangkapan yang tidak merusak ekosistem laut. 


\section{KESIMPULAN}

Hasil penelitian menunjukkan bahwa masyarakat adat Raja Ampat merupakan masyarakat tradisional yang hidupnya sangat akrab dan harmonis dengan alam terutama alam laut dan perairan sehingga kearifan lokal (local wisdom)dan pengetahuan tradisional (local knowledge) tumbuh dan berkembang serta terpelihara dengan baik pada masyarakatnya seperti Sasi. Sasi sebagai kearifan lokal (local wisdom) masyarakat lokal Raja Ampat pernah hidup dan menjadi bagian yang tak terpisahkan dalam keseharian mereka sebagai nelayan namun mati dengan adanya interaksi dengan dunia luar terutama nelayan yang memperkenalkan teknologi tangkap modern.

Kerusakan ekosistem perairan sebagai akibat model penangkapan ikan yang tidak ramah lingkungan membuat pemangku kepentingan seperti: Pemerintah Daerah, LSM, industri pariwisata) mencari solusi dan langkah terbaik menanggulangi bencana kerusakan tersebut maka lahirlah budaya konservasi perairan Raja Ampat dengan sistem zonasi. Upaya melindungi dan menjamin masa depan generasi baru Raja Ampat, maka Sasi dibangkitkan kembali sebagai strategi pengelolaan dan manajemen perairan yang berbasiskan masyarakat lokal untuk menjadi garda terdepan dalam perlindungan dan pengelolaan surga terumbu karang terakhir di bumi.

\section{UCAPAN TERIMA KASIH}

Penelitian ini di danai oleh Beasiswa BUDI_ DN Kemenkeu-RI Tahun 2016 dan merupakan penggalan-penggalan fenomena sosial budaya yang diteliti di lokasi penelitian yang bukan merupakan lingkup penelitian disertasi yang sedang dilakukan di Raja Ampat.

\section{Daftar Pustaka}

Bailey, C., \& Zerner, C. (1991). Role of Traditional Fisheries Resource Management System for Sustainable Resources Utilization. Centre for Research Institute of Fisheries.

Bourdieu, P. (2010). Arena Produksi Kultural, Sebuah Kajian Sosiologi Budaya. Kreasi Wacana.
Giddens, A. (2011). Runaway World. Profile Books.

Kaplan, D., \& Manners, A. A. (1999). Teori budaya. Pustaka Pelajar.

Koentjaraningrat. (2008). Sejarah teori antropologi (Volume 1). Penerbit Universitas Indonesia.

Mcleod, E. (2007). Traditional Marine Resource Management In Raja Ampat, Indonesia [University of Hawwai]. https:// birdsheadseascape.com/wp-content/ uploads/McLeod07_FinalThesis_RajaAmpat.pdf

Miles, M. B., \& Huberman, A. M. (2009). Analisis Data Kualitatif: Buku Sumber Tentang Metode-Metode Baru. UI Press.

Patria, N. (2003). Antonio Gramsci : Negara dan Hegemoni. Pustaka Pelajar.

Pattiselanno, F., \& Mentansan, G. (2010). Kearifan Tradisional Suku Maybrat Dalam Perburuan Satwa Sebagai Penunjang Pelestarian Satwa. Makara, Sosial Humaniora, 14(2), 75-82. http://hubsasia. ui.ac.id/old/index.php/hubsasia/article/ view/664

Permana, C. E., Nasution, I. P., \& Gunawijaya, J. (2011). Kearifan Lokal Tentang Mitigasi Bencana pada Masyarakat Baduy. Makara, Sosial Humaniora, 15(1), 67-76. http://hubsasia.ui.ac.id/old/index.php/ hubsasia/article/view/45

Prastowo, A. (2014). Jual Metode Penelitian Kualitatif; dalam Perspektif Rancangan Penelitian. Ar-Ruzz Media.

Prihandoko, Jahi, A., Gani, D. S., Purnaba, I. G. P., Adrianto, L., \& Tjitradjaja, I. (2011). Faktor-Faktor yang Mempengaruhi Perilaku Nelayan Artisanal Dalam Pemanfaatan Sumberdaya Perikanan di Pantai Utara Provinsi Jawa Barat. Makara, Sosial Humaniora, 15(2), 117-126. http://hubsasia.ui.ac.id/old/index.php/ hubsasia/article/view/1418

Snijders, A. (2004). Antropologi Filsafat Manusia : Paradoks dan Seruan. Kanisius.

Sztompka, P. (2005). Sosiologi Perubahan Sosial. Prenada Media.

Yudhie, H. (2005). Melawan dengan Teks. Resist Book. 